\title{
Antibiotic Therapy
}

National Cancer Institute

\section{Source}

National Cancer Institute. Antibiotic Therapy. NCI Thesaurus. Code C15620.

Treatment of bacterial infections with antibiotics. 